Journal of Tourism Theory and Research

Online, http://dergipark.gov.tr/jttr

Volume: 5(2) Futourism, 2019

ISSN: $2548-7583$

\title{
Using the seemingly unrelated regression model in the estimation of tourism demand of Turkey
}

Halil İbrahim Keskin ${ }^{1}$

\begin{abstract}
In the tourism sector, various methods are used to investigate demand for countries. In this study aimed to investigate the demand for tourism to Turkey from selected countries for the period 1984 - 2014 by using Seemingly Unrelated Regression (SUR) method. To analyze the tourism demand towards Turkey, the countries sending the most tourists to Turkey like the United Kingdom, Germany, Commonwealth of Independent States and Iran are selected. To explain the tourism demand from these countries to Turkey, it has benefited from traditional demand model. According the results obtained, Turkey's tourism price index doesn't seem to explain the demand statistically significant. Another result obtained from the study shows an increase in rival countries' price index increases the demand for Turkey. Also, an increase in the income level of the countries sending tourist seems to increase the tourism demand in general. In addition, it is seen that the price is a decisive factor when it is preferred among alternative countries for holidays in countries with low per capita income levels.
\end{abstract}

Keywords: Seemingly Unrelated Regression, Tourism Demand, Panel Data

Türkiye'nin turizm talebinin tahmininde görünürde ilişkisiz regresyon modelinin kullanılması

$\ddot{\boldsymbol{O}} \boldsymbol{z}$

Turizm sektöründe, ülkelere yönelik talebin araştırılmasında çeşitli yöntemler kullanılmaktadır. Bu çalışmada seçilmiş ülkelerden 1984 - 2014 dönemi için Türkiye’ye yönelik turizm talebinin Görünürde İlişkisiz Regresyon (GIR) yöntemiyle araştırllması amaçlanmaktadır. Türkiye'ye yönelik turizm talebini araştırmak için Ingiltere, Almanya Bağımsız Devletler Topluluğu ve Iran gibi Türkiye'ye en çok turist gönderen ülkeler seçilmiştir. Bu ülkelerden Türkiye'ye yönelik turizm talebini açıklamak için geleneksel talep modelinden yararlanılmıştır. Elde dilen sonuçlara göre, Türkiye'deki turizm fiyat endeksinin talebi anlaml bir şekilde açıklamadiğı görülmektedir. Çalışmada elde edilen diğer bir sonuç, rakip ülkelerin fiyat endeksindeki artışın, Türkiye’ye olan turizm talebini arttırmadı̆̆ını göstermektedir. Ayrıca, turist gönderen ülkelerin gelir düzeyindeki artış genel olarak talebi arttırmaktadır. Dahası, kişi başına gelir seviyesi düşük olan ülkelerde tatil için alternatif ülkeler arasında tercih yaparken fiyatın belirleyici bir faktör olduğu görülmektedir.

Anahtar sözcükler: Görünürde İlişkisiz Regresyon, Turizm Talebi, Panel Veri

Geliş Tarihi $\quad: 27.09 .2018$

Kabul Tarihi $\quad: 01.03 .2019$

Alıntı için: Keskin, H.İ. (2019). Türkiye'nin turizm talebinin tahmininde görünürde ilişkisiz regresyon modelinin kullanılması. Journal of Tourism Theory and Research, 5(2), 182-190.

${ }^{1}$ Arş. Gör. Dr., Çukurova Üniversitesi, IIIBF, Ekonometri Bölümü, Adana/Türkiye, hkeskin@,cu.edu.tr 


\section{Giriş}

Dünyada, turizm sektörünün ekonomideki etkisi son yıllarda oldukça önemli hale gelmiştir. Özellikle 1990'l1 y1llardan sonra turizmin GSMH içerisindeki payı yıldan yıla artış göstermektedir. 2014 verilerine göre turizm dünya GSMH toplamı içerisinde $\% 21,8$ gibi önemli bir paya ulaşmıştır. Turizm sektörü gelişmiş ve gelişmekte olan ülkelere döviz girdisi sağlamasının yanında üretimde çeşitliliğe katkı sağlamaktadır. Bunun yanında, özellikle, istihdam oluşturarak işsizliği azaltılmasına yönelik önemli katkılar sağlaması bakımında oldukça önemlidir. Turizm sektörü, ayrıca, gelişmekte olan ülkelerin kalkınma ve büyüme için ihtiyaç duyduğu döviz girdisine önemli bir katkı sağlamaktadır. Bu katkıları sayesinde son yıllarda dünyadaki neredeyse tüm ülkeler turizme önem vermeye başlamıştır. Türkiye'de ise turizm 1985 y1lından sonra önemli bir atılım gerçekleştirmiş. Özellikle 2000'li yıllardan sonraki on üç yıllık dönemde Türkiye'nin turizm gelirlerinde $\% 236^{\circ} \mathrm{l} 1 \mathrm{k}$ bir artış meydana gelmiştir (Şen \& Şit, 2015). Türkiye'nin uluslararası turizm gelirlerinden aldığ 1 pay da bu dönemde artmıştır. Turist sayısı bakımından bu dönemde yirminci sıradan yedinci suraya yükselerek, Türkiye'nin önemli bir turist çeken ülke olma başarısı elde ettiği görülmektedir (Şen \& Şit, 2015). Bu başarının sürdürülebilmesi için Türkiye'ye yönelik turizm talebinin belirlenmesi hem turizm planlamalarının yapılması hem de turizm politikalarının belirlenmesi açısından oldukça önemlidir.

Turizm talebini araştıran çalışmalarda yöntem olarak klasik regresyon analizi yöntemi, zaman serisi modelleri veya yapay sinir ağları gibi çeşitli yöntemler kullanılmasının yanında, sahip olduğu avantajlardan dolayı görünürde ilişkisiz regresyon (GİR) yöntemi alternatif bir yöntem olarak öne çıkmaktadır. Görünürde ilişkisiz regresyon yöntemi, aralarında ilişki bulunan birden fazla bağımlı değişken ile aralarında doğrusal ilişki bulunmayan çok sayıda açıklayıcı değişken arasinda oluşturulan regresyon modelidir. GİR modeli her bir bağımlı değişken için ayrı ayrı oluşturulan denklemlerin hata terimleri arasında ilişki olması durumunda kullanılan bir yöntemdir. Böyle bir durumda s1radan en küçük kareler tahmin yönteminin kullanılması, parametre tahminlerinin etkinliğinin bozulması gibi sorunlara neden olmaktadır. Zellner (1962) tarafindan ilk olarak önerilen görünürde ilişkisiz regresyon yöntemi genelleştirilmiş en küçük kareler tahmincisi kullanarak regresyonların hata terimleri arasındaki ilişkiyi dikkate alabilen bir yöntemdir. Bu yöntemin özellikle birden fazla ürüne veya hizmete yönelik talep araştırmalarında birçok farklı sektörde kullanıldığı görülmektedir. Tek denklemli sıradan en küçük kareler yöntemiyle her bir ülkeden, seçilen ülkeye yönelik turizm talebinin araştırıldığı bir çalışmada farklı ülke talepleri arasında bir ilişki olmadığını varsaymak pek gerçekçi değildir. Dolayısıyla bu denklemlerin ayrı ayrı tahmininden elde edilen hata terimleri arasinda ilişki olması muhtemeldir. Ancak literatürde bu durumu dikkate alan oldukça az sayıda çalışma bulunmaktadır. Türkiye'de ise GİR yöntemi kullanılarak turizm talebinin araştırıldığı Aksakal ve Çilan (2015) tarafından yayınlanmış makale dışında herhangi bir çalışmaya rastlanmamıştır. Dolayısıyla bu çalışmada seçilmiş ülkelerden 1984- 2014 arası dönem için Türkiye’ye yönelik turizm talebinin görünürde ilişkisiz regresyon yöntemiyle araştırılması amaçlanmaktadır. Böylece panel verinin kullanıldığg turizm talebiyle ilgili araştırmalarda GİR yönteminin kullanılmasının sağlayacağı avantajlar bakımında bu alandaki literatürün gelişmesine katı sağlayacağı düşünülmektedir.

\section{Literatür}

Turizm ekonomisi literatüründe, ülkelere yönelik turizm talebini ve talebi etkileyen faktörleri inceleyen çok sayıda çalışma ve yönteme rastlamak mümkündür. Song ve Lee (2008) çalışmasında 2000 yılından itibaren turizm literatüründe kullanılan yöntemlere ilişkin bir literatür özeti sunmaktadır. Literatür özetinde belirtilen yöntemler arasında Rufino (2011), Baldigara (2013) gibi ekonometrik zaman serisi yöntemleri kullanan çalışmaların yanında Vanegas (2009), Ziramba ve Moyo (2013) gibi klasik regresyon analizini yöntem olarak tercih eden çalışmalara da rastlamak mümkündür. Türkiye'de ise turizm talebi tahmininde tercih edilen yöntemler çoğunlukla En Küçük Kareler (EKK), zaman serisi yöntemleri ve Yapay Sinir Ağları (YSA) yöntemleridir, Önder vd. (2009), Soysal ve Ömürgönülşen (2010) ve Çuhadar (2013).

GİR yöntemi ilk olarak Zeller (1962) tarafindan geliştirilmiştir. Zellner birden fazla bağımlı değișene sahip regresyon modelini tek denklemli bir formda ifade etme çalışmaları sonucunda GİR modelini geliştirmiştir. Regresyon sistemindeki her bir denklemi ayrı ayrı 
tahmin etmek yerine denklemleri bir arada Genelleştirilmiş En Küçük Kareler (GEKK) yöntemiyle tahmin etmenin daha etkin sonuçlar verdiğini göstermiştir. Sonraki yıllarda bu yöntem birçok çalışmayla çeşitli yönleriyle araştırılmıştır. Zellner ve Huang (1962) ve Kmenta (1986) çalışmalarıyla Zellner'in iddiasını test ederek, GIR modelinin tahmininde GEKK yönteminin etkinliğini araştırmışlardır. Baltagi vd., (1989) ve Hwang (1990) ise dengeli olmayan panel veri durumunda, yani eşit sayıda olmayan gözlemden oluşması durumunda geçerli tahminciler üzerine çalışmışlardır. Srivastava vd. (1979) ise modelin hata teriminde otokorelasyon olması, çoklu doğrusallık ve belirleme hatası gibi varsayımların ihlali durumları üzerinde çalışmıştır. Bunun dışında birçok araştırmacı GİR modelinin tahmini için çeşitli tahminciler önermiştir. Bunlardan bazılar1; Kontoghiorghes ve Clarke (1995), Smith ve Kohn (2000) çalışmalarıdır.

GİR modeli özellikle mikro iktisadi çalışmalarda oldukça yaygın kullanılmaktadır. Özellikle ticari ürünlere yönelik talep araştırmalarında, finansal varlık fiyatlama modelleri veya birden fazla firmaya ya da sektöre yapılacak yatırım modelleri gibi araştırmalarda tercih edilen bir yöntemdir. Turizm ekonomisi literatüründe bu yöntemin kullanıldığı oldukça sınırlı sayıda çalışma bulunmaktadır. Literatürde turizm talebi ve bu talebi etkileyen faktörlerin GİR yöntemiyle araştırıldığı çalışmalardan Syriopoulos ve Thea (1993) makalesi Neredeyse İdeal Talep Sistemi (AIDS) modelini GİR yöntemiyle tahmin etmiştir. Çalışmada simetri ve heterojenlik kısıtları reddedilse bile yöntemin ekonometrik olarak tatmin edici olduğunu belirtilmektedir. Benzer şekilde AIDS modelinin tahmininde GİR yönteminin kullanıldığ 1 diğer çalışmalar ise O'Hagan ve Harrison (1984a; 1984b) çalışmalarıdır. Chen ve Soo (2007), Tayvan uluslararası otel endüstrisinin maliyet fonksiyonunu iteratif GIIR ve üç aşamalı EKK yöntemleriyle tahmin etmiştir. Salman vd. (2010) çalışmasinda seçilen beș ülkeden İsveç ve Norveç'e yönelik turizm talebini İteratif GIR yöntemiyle araştırmıştır. Sonuçta göreli fiyatlar ile döviz kurunun uluslararası turizm talebi üzerinde anlamlı bir etkiye sahip olduğu bulunmuştur. Mehmetoğlu (2010) çalışmasında ise GİR yöntemiyle turistlerin kendi ülkelerinde ve gittiği yerlerdeki çevre dostu davranışa heveslerinin belirleyicilerini araştırmışlardır. Literatürde Türkiye'ye yönelik turizm talebinin GİR yöntemiyle araştırıldığı yal- nızca bir tane çalışmaya rastlanmıştır. Aksakal ve Çilan (2015) çalışmasında ise Türkiye'ye en fazla turistin geldiği Avrupa ülkelerinden Türkiye'ye yönelik turizm talebini GİR modeli ile inceleyerek, elde ettiği sonuçları EKK ile karşılaştırılmıştır. GİR modelinin klasik regresyon modeliyle elde edilen tahmin sonuçlarından daha etkin sonuçlar verdiğini bulmuştur. Bu çalışmada 1984-2010 dönemi dikkate alınarak İngiltere, Almanya, BDT ve İran'dan Türkiye'ye yönelik turizm talebinin GIR yöntemiyle araştırılması amaçlanmaktadir.

\section{Yöntem}

GIR modeli birden fazla bağımlı değişken ile bir ya da daha fazla bağımsız değișken arasındaki regresyon durumudur. $n$ gözlem sayılı, 2 tane bağımlı değişkenden ve 3 tane bağımsız değişkenden oluşan bir GİR modeli matris formunda aşağıdaki gibi gösterilir.

$\left[\begin{array}{cc}y_{11} & y_{12} \\ y_{21} & y_{22} \\ \vdots & \vdots \\ y_{n 1} & y_{n 2}\end{array}\right]=\left[\begin{array}{cccc}1 & x_{11} & x_{12} & x_{13} \\ 1 & x_{21} & x_{22} & x_{23} \\ \vdots & \vdots & \vdots & \vdots \\ 1 & x_{n 1} & x_{n 2} & x_{n 3}\end{array}\right] \cdot\left[\begin{array}{cc}\beta_{01} & \beta_{02} \\ \beta_{11} & \beta_{12} \\ \beta_{21} & \beta_{22} \\ \beta_{31} & \beta_{32}\end{array}\right]+\left[\begin{array}{cc}\varepsilon_{11} & \varepsilon_{12} \\ \varepsilon_{21} & \varepsilon_{22} \\ \vdots & \vdots \\ \varepsilon_{n 1} & \varepsilon_{n 2}\end{array}\right]$

GIR modeli matris formunda genel olarak aşağıdaki gibi yazılır:

$Y=X B+\Xi$

Burada,

$$
\begin{aligned}
& Y: n \times p \\
& X: n \times(q+1) \\
& B:(q+1) \times p \\
& \Xi: n \times p
\end{aligned}
$$

Modelin tahmini için gerekli varsayımlar:

i. Her bir denklemdeki hata terimlerinin beklenen değeri sıfira eşittir ve normal dağılıma sahiptir.

ii. $\mathrm{X}$ matrisi sabit ranklıdır, $\mathrm{n}$.

iii. Farklı denklemlerdeki hatalar birbiriyle ilişkili olabilir, $E\left(\varepsilon_{m} \varepsilon_{p}^{\prime}\right)=\sigma_{m p} I_{n}$.

iv. $\mathrm{X}$ matrisi stokastik değildir. Bu nedenle $\mathrm{X}^{\prime} \mathrm{X}$ matrisi tekil değildir.

GIR modelindeki her bir denklem EKK varsayımlarını sağlarken, EKK dıșında iii. varsayımda belirtildiği farklı denklemlerdeki hata terimleri arasında ilişkiye izin verebilmektedir. 
GİR modeli yukarda verilen modeldeki her bir bağımlı değişken için ayrı ayrı denklemler oluşturarak, EKK yöntemiyle tahmin edilebilir. Ancak denklemler arasındaki hata terimlerinin korelasyonunun yüksek olması ve farklı denklemlerdeki açıklayıcı değişkenlerin birbirleriyle ilişkisiz olması durumunda GİR modelini oluşturan denklemlerin ortak tahmini, her denkleme ayrı ayrı uygulanan En Küçük Kareler (EKK) yöntemine göre daha etkin tahminler verecektir. Çünkü EKK yöntemi ile yapılan tahmin, yansız, tutarlı ancak etkin olmayan parametre tahminlerine neden olmaktadır. Denklemlerin hataları arasındaki korelasyonu dikkate alabilen Genelleştirilmiş En Küçük Kareler (GEKK) yöntemi tahminin etkinliğini arttırmaktadır. (Aksakal \& Çilan, 2015).

GİR modeli Genelleştirilmiş EKK (GEKK) ile tahmin edilmektedir. GEKK yönteminde hata terimlerinin varyans-kovaryans matrisi regresyona dahil edilmektedir. Uygulamalı çalışmalarda varyans kovaryans matrisindeki elemanlar bilinmemektedir. Zellner bunun yerine her bir denklemi ayrı ayrı EKK yöntemiyle tahmininden elde edilen hata terimlerini kullanmıştır. Daha sonra varyans kovaryans matrisinin tahmini $\beta$ 'nın tahmincisinde kullanılarak, GİR modelinin GEKK tahmincisi aşağıdaki gibi elde edilmektedir.

$$
\widehat{\beta}_{G E K K}=\left(X^{\prime} \Omega^{-1} X\right)^{-1} X^{\prime} \Omega^{-1} Y
$$

Bu tahmin ediciye Zellner tahmin edicisi ya da Aitken'in iki aşamalı genelleştirilmiş en küçük kareler tahmincisi de denilmektedir. Burada $\beta$ 'nın tahmin edicisi matris gösteriminde aşağıdaki gibi verilmektedir.

$$
\widehat{\beta}=\left[\begin{array}{c}
\beta_{1}^{\prime} \\
\beta_{2}^{\prime} \\
\vdots \\
\beta_{n}^{\prime}
\end{array}\right]=\left[\begin{array}{ccc}
s^{11} X_{1}^{\prime} X_{1} & \cdots & s^{1 M} X_{1}^{\prime} X_{M} \\
s^{21} X_{2}^{\prime} X_{1} & \cdots & s^{2 M} X_{2}^{\prime} X_{M} \\
\vdots & \ddots & \vdots \\
s^{M 1} X_{M}^{\prime} X_{1} & \cdots & s^{M M} X_{M}^{\prime} X_{M}
\end{array}\right]^{-1}\left[\begin{array}{c}
\sum_{i=1}^{M} s^{1 m} X_{1}^{\prime} Y_{j} \\
\sum_{i=1}^{M} s^{2 m} X_{2}^{\prime} Y_{j} \\
\vdots \\
\sum_{i=1}^{M} s^{M m} X_{M}^{\prime} Y_{j}
\end{array}\right]
$$

$\mathrm{Bu}$ modelin tahmini en çok olabilirlik yöntemiyle de yapilabilmektedir (Sezer, 2006).

\section{Veri seti \& model}

Bu çalışmada, Türkiye'ye yönelik turizm talebini araştırmak için iktisat literatüründeki geleneksel talep denklemi olarak adlandırılan model kullanılmıştır. Geleneksel talep teorisi, temel olarak, talebi açıklayan dört faktör üzerinde durmaktadır: Malın kendi fiyatı, diğer malların fiyatları, tüketici geliri, tüketici zevk ve tercihleri. Bu değişkenlerin iktisadi olarak talep üzerindeki beklenen etkileri, diğer değişkenler sabitken, sirasıyla talep edilen malın fiyatı artarsa o mala olan talep azalır, ikame malın fiyatı artarsa o mala olan talep artar, gelecekteki fiyat ve gelir düzeyine ilişkin beklentiler artarsa mala olan talep artar şeklindedir. Turizm talebi ise farklı şekillerde ifade edilebilir. Ekonomik faktörlerle turizm talebini açıklayan en uygun değişken tüketici harcamalarıdır (Grouch, 1992). Turizm talebinin diğer bir ölçüsü geçirilen gece sayısı veya kalış süresi değişkenleridir. Bu çalışmada seçilmiş ülkelerden 1984- 2014 arası dönem için Türkiye'ye yönelik turizm talebinin ölçüsü olarak Türkiye'ye gelen en az bir gece konaklayan turist sayıları kullanılmıştır.

Turizm talebini araştıran çalışmalarında yaygın olarak kullanılan model, talebin turistin ülkesindeki geliri, seçtiği ülkedeki turizm maliyeti ve ikame fiyat olarak alternatif seçeneklerin maliyetiyle açiklayan tek denklemli modeldir (Witt \& Martin, 1987). Ancak bu çalışmada geleneksel talep modelinden farklı olarak ele al1nan her bir ülke için çok denklemli bir model kullanılmaktadır. Buna göre, çalışmada kullanılan geleneksel talep denklemi çerçevesinde GİR modeli formunda oluşturulmuş model aşağıdaki gibi verilmiştir.

[lneng, lnger, lnbdt, lnıran] $=\beta_{0}+\beta_{1} \ln I F+\beta_{2} \ln R C S I+\beta_{3} \ln g d p$

Modeldeki bağımlı değişkenler ilgili ülkelerden Türkiye'ye gelen ve en az bir gece konaklayan toplam turist sayısını göstermektedir. Bağımsız değişkenler ise, Türkiye'ye turizmde rakip olan Akdeniz'e kiyısı olan ülkelerin fiyat indeksi, ikame fiyat (IF-2000 fiyatları ile), ilgili ülkenin kişi başına reel geliri (GDP-2000 fiyatları ile) ve Türkiye'nin turizm fiyat indeksi (RCSI2000 fiyatları ile) değişkenleridir. Kullanılan veriler Dünya Kalkınma Göstergesi (WDI) veri tabanı, Kültür ve Turizm Bakanlığ Kurumundan derlenmiştir. Parasal değişkenler reel olup, değişkenler logaritmik değerleri ile işlem görmüşlerdir.

Türkiye'nin turizm fiyat indeksi aşağıdaki formülle elde edilmiştir:

$$
R C S I=\frac{C P I_{T u r} / E X_{T u r}}{C P I_{W}}
$$


$C P I_{T u r}$, Türkiye'nin tüketici fiyat indeksi

$C P I_{T u r}$, Dünya'nın tüketici fiyat indeksi

$\mathrm{EX}_{T u r}$, Türkiye'nin döviz kuru

Rakip ülkelerin fiyatları ise aşağıdaki formül kullanılarak hesaplanmıştır:

$$
I F_{t}=\sum_{j=1}^{11}\left(\frac{C P I_{j}}{E X_{j}}\right) w_{j}
$$

Burada,

$$
w_{j}=\left[\frac{T T S_{j}}{\sum_{j=1}^{3} T T S_{j}}\right]
$$

$C P I_{J}$, rakip ükelerin tüketici fiyat indeksleri

$\mathrm{EX}_{j}$, rakip ülkelerin döviz kurları

$\mathrm{w}_{j}$, rakip ülkelerin Türkiye'nin toplam turist gelişler

$\mathrm{TTS}_{J}$, J ülkesinden Türkiye'ye gelen toplam turist š́

J: Turizmde Türkiye'ye rakip olan ülkeler (Yunanistan, İtalya, Fransa, İspanya, Libya, Misır, İsrail) (Selim \& Demir, 2009).
Modeldeki katsayılara ilişkin beklentilerimiz; rakip ülkelerin turizm fiyat indeksi attığında Türkiye'ye gelecek olan turist sayısında bir artış beklenmektedir. $\mathrm{Bu}$ endeks talep denklemindeki rakip malların fiyatları gibi yorumlanabilmektedir. Bu yüzden pozitif beklenmektedir. Toplam gelir düzeyi arttığında yine Türkiye'ye gelecek olan turist sayısında bir artış beklenir. Türkiye'nin turizm fiyat indeksinin katsayısı ise Türkiye'deki turizme ilişin fiyatları temsil ettiğinden, fiyatlar arttığında gelecek olan turist sayısında bir azalma olacağında bu katsayının negatif işaretli olması beklenmektedir.

\section{Bulgular}

Çalışmada, öncelikle İngiltere, Almanya, BDT ve İran için oluşturulan denklemlerin hata terimleri arasindaki korelasyon Breusch-Pagan (1979) testiyle incelenmiştir. Elde edilen sonuçlara göre test istatistiği değeri 20.48 olarak bulunmuştur. Bu sonuç denklemlerin hata terimleri arasında yüksek korelasyon olduğuna işaret etmektedir. Bu sonuç GİR modelinin kullanılması gerekliliğini işaret etmektedir.

Seçilmiş ülkelerden Türkiye'ye yönelik turizm talebini araştırmak için tahmin edilen SUR modeline ait sonuçlar Tablo1'de verilmiştir.

\begin{tabular}{|c|c|c|c|}
\hline \multirow{6}{*}{ lneng } & Değişkenler & Katsayılar & P-değeri \\
\hline & Lnif & 0,076 & $0,03 * *$ \\
\hline & Lnrcsi & $-0,049$ & 0,71 \\
\hline & Lngdp & 1,718 & $0,00 * * *$ \\
\hline & Sabit & $-26,12$ & $0,00 * * *$ \\
\hline & $\mathrm{F}=124,12$ & F-Prob:0,00* & \\
\hline \multirow{5}{*}{ lnger } & Lnif & 0,064 & $0,02 * *$ \\
\hline & Lnrcsi & $-1,219$ & 0,51 \\
\hline & Lngdp & 1,987 & $0,00 * * *$ \\
\hline & Sabit & $-29,41$ & $0,00 * * *$ \\
\hline & $\mathrm{F}=141,77$ & F-Prob:0,00* & \\
\hline \multirow{5}{*}{$\operatorname{lnbdt}$} & Lnif & 4,101 & $0,01 * *$ \\
\hline & Lnrcsi & 1,109 & 0,24 \\
\hline & Lngdp & 3,341 & $0,00 * * *$ \\
\hline & Sabit & $-34,19$ & $0,00 * * *$ \\
\hline & $\mathrm{F}=98,13$ & F-Prob:0,00* & \\
\hline \multirow{5}{*}{ lniran } & Lnif & $-0,020$ & $0,06^{*}$ \\
\hline & Lnrcsi & $-0,097$ & 0,63 \\
\hline & Lngdp & 3,174 & $0,00 * * *$ \\
\hline & Sabit & $-43,79$ & $0,00 * * *$ \\
\hline & $\mathrm{F}=96,82$ & F-Prob:0,00* & \\
\hline
\end{tabular}

Tablo 1. GİR Modeli Tahmin Sonuçları,1984-2014

Not: *** \%1, **\%5,*\%10 anlam seviyesinde anlamlı olduğu göstermektedir. Ineng: İngiltere, lnger: Almanya, lnbdt: Bağımsız Devletler Topluluğu ve lniran: İran anlamına gelmektedir. Bağımlı değişkenler çalışmada dikkate alınan ülkelerden Türkiye'ye gelen turist sayılarıdır. 
Elde edilen bulgulara göre lnrcsi değişkeni tüm modellerde pozitif fakat anlamsızdır. Bu bulgu Türkiye'nin turizm fiyat endeksinin Türkiye'ye yönelik turizm talebini açılamada anlamlı bir etkiye sahip olmadığını göstermektedir. Çalışmada elde edilen diğer bir bulgu, rakip ülkelerin turizm fiyat endeksinde meydana gelen yüzde 1'lik bir artışın, İngiltere'den Türkiye'ye yönelik turizm talebini \%0,76. Almanya'dan Türkiye'ye yönelik turizm talebini \%0,64, Bağımsız devletler topluluğundan Türkiye'ye yönelik turizm talebini ise yüzde 4,1 arttırdığını göstermektedir. Ancak, İran'dan Türkiye'ye yönelik turizm talebini $\% 0,2$ oranında azaltmaktadır. Bu sonuç İran'ın rakip ülkelerin fiyat endeksindeki artışın Türkiye'ye olan talebi azalttığını göstermektedir. Bu sonuç beklentilerin aksine İran'dan Türkiye'ye olan talebin diğer Akdeniz ülkelerindeki fiyat artışından negatif etkilendiğini göstermektedir. Bunun nedeni Türkiye'nin alternatifi olan Akdeniz bölgesindeki diğer ülkelerde fiyat artışına bağlı olarak Türkiye'nin de aynı dönemde kısmen fiyat artışına gitmiş olabileceği ve bu nedenle İran'dan Türkiye'ye talebin azalmış olabileceği şeklinde açıklanabileceği gibi İran'ın bu ülkeleri tatil için tercih etmediği şeklinde de açıklanabilmektedir. Ayrıca çalıșmada ele alınan her bir ülkenin gelir seviyesinde meydana gelen artışın, beklendiği gibi bu ülkelerden Türkiye'ye olan talebi arttırmaktadır. Bunun yanında özellikle İran ve Bağımsız devletler topluluğuna ait ülkelerin gelir düzeyinin artması Türkiye'ye yönelik turizm talebini, modeldeki diğer Avrupa ülkelerine göre daha fazla arttırmaktadır.

Çalışmada, ayrıca, tahmin edilen modele ilişkin tanısal testler yapılarak, elde edilen sonuçların gerekli varsayımları sağlayıp sağlamadığı araştırılmıştır. Tablo2'de verilen alternatif test sonuçlarına göre modelin artıkları varsayıma uygun olarak normal dağılıma uymaktadır.

Tablo 2. Artıkların Normal Dağılımdan Gelip Gelmediğine İlișkin Test Sonuçları

\begin{tabular}{lc}
\hline Shapiro Wilk W testi & 0,952 \\
\hline P Değeri & 0,244 \\
\hline
\end{tabular}

Modellerdeki açıklayıcı değişkenler arasında çoklu doğrusallık sonunun varlığının sınanması için varyans büyütme faktörü (VIF) hesaplanmıştır. Elde edilen sonuçlar Tablo3'de verilmiştir.
Tablo 3. Çoklu Doğrusallık Testi Sonuçları

\begin{tabular}{lll}
\hline Model & Değişken & VIF \\
\hline Lneng & Lnif & 4,91 \\
& Lngdp & 4,68 \\
& Lnrcsi & 1,14 \\
\hline \multirow{2}{*}{ Lnger } & Lnif & 4,91 \\
& Lngdp & 4,68 \\
& Lnrcsi & 1,14 \\
\hline Lnbdt & Lnif & 4,91 \\
& Lngdp & 4,68 \\
& Lnrcsi & 1,14 \\
\hline \multirow{2}{*}{ Lniran } & Lnif & 4,91 \\
& Lngdp & 4,68 \\
& Lnrcsi & 1,14 \\
\hline
\end{tabular}

Tablodaki tüm VIF değerleri 10'dan küçük olduğu için bu sonuç bağımsız değişkenler arasında çoklu doğrusallık sorunu bulunmadığını işaret etmektedir.

Çalışmada ayrıca, her bir model artıkları için otokorelasyon sorununun sinanması için Durbin Watson testi gerçekleştirilmiștir. Elde edilen test sonuçlarına göre modellerde artıklara ilişkin otokorelasyon sorununa rastlanmamıştır.

Tablo 4. Otokorelasyon Testi Sonuçları

\begin{tabular}{cc}
\hline Model & Durbin Watson Testi Değeri \\
\hline Lneng & 0,91 \\
Lnger & 0,58 \\
Lnbdt & 0,99 \\
Lniran & 0,96 \\
\hline
\end{tabular}

Çalışmada ayrıca her bir modelin artıkları için değişen varyans sorununun (heteroscedasticity) varlığını sınanmak üzere ARCH-LM testi gerçekleștirilmiștir. Elde edilen test sonuçları Tablo5'te verilmiştir.

Tablo 5. Değişen Varyans Testi Sonuçları

\begin{tabular}{lcl}
\hline Model & ARCH-LM Testi Değeri & P-Değeri \\
\hline Lneng & 0,479 & 0,49 \\
Lnger & 0,088 & 0,76 \\
Lnbdt & 5,356 & 0,52 \\
Lniran & 0,208 & 0,64 \\
\hline
\end{tabular}

ARCH-LM testi sonuçlarına göre modellerin tümünde değişen varyans sorununa rastlanmamıştır. Özetle, modelin ve elde edilen modelin sonuçlarının geçerliliğine ilişkin yapılan tanısal testler modelde önemli bir sorun bulunmadığını göstermektedir.

\section{Sonuc}

Bu çalışmada 1984- 2010 arası dönem için İngiltere, Almanya, BDT ve İran'dan Türkiye'ye olan turizm talebi GİR yöntemiyle araştırılmıştır. Bunun için öncelikle her ülkeden Türkiye'ye yönelik turizm talebi 
için oluşturulan modellerin hata terimleri arasındaki ilişkinin varlığının araştırılmış ve yüksek ilişki buluşmuştur. Bu sonuç GİR modelinin kullanılmasının gerekli olduğunu belirtmektedir. GIR modeli tahmininden elde edilen sonuçlara göre Türkiye'nin fiyat endeksi tüm denklemlerde anlamsız bulunmuştur. Bu sonuç, Türkiye'nin fiyat azaltarak talebi anlamlı bir şekilde arttıramayacağını göstermektedir. Diğer taraftan rakip ülkelerin fiyat endeksinin artması, İran hariç diğer ülkelerden Türkiye'ye olan talebi arttırmaktadır. Diğer bir bulgu ise gelir değişkeninin beklentilere uygun olarak Türkiye'ye olan turizm talebini arttırdığıdır.

Özellikle Türkiye'ye rakip ülkelerin turizme fiyat endeksinde meydana gelecek artış, Bağımsız devletler topluluğuna (BDT) ait ülkelerden Türkiye olan talebi oldukça arttırmaktadır. Bunun yanında İngiltere Almanya gibi gelişmiş ülkelerden Türkiye'ye olan talep artış1 BDT ülkelerine göre oldukça düşük olduğu bulunmuştur. Bu sonucun Keskin (2018)'in 1984-2010 arası veriyle ve çok değişkenli çoklu regresyon analizi kullanarak elde ettiği sonuçlara benzer olduğu görülmektedir. Ayrıca gelir seviyesi düşük olan ülkelerin rakip ülke fiyatlarından gelir seviyesi yüksek olan ülkelere göre daha fazla etkilenmesi beklenen bir sonuçtur. $\mathrm{Bu}$ sonuç kişi başına gelir seviyesi düşük olan ülkelerde tatil için alternatif ülkeler arasında tercih yaparken fiyatın belirleyici bir faktör olduğunu göstermektedir. Ancak, İran'dan Türkiye'ye yönelik turizm talebini açıklamada rakip ülke fiyatlarının artmasının Türkiye'ye olan talebi azaltması teorik beklentilerle uyuşmamaktadir.

$\mathrm{Bu}$ çalışmada rakip ülke olarak seçilen ülkelerin İranlı turistler tarafindan Türkiye'ye bir alternatif olarak görülmemesi ya da Akdeniz ülkelerinin sunduğu deniz turizminin İranlı turistler tarafindan çok fazla tercih edilmemesi gibi durumu ortaya çıkmaktadır. Bununla beraber, bu sonucun ortaya çıkmasında Akdeniz bölgesindeki ülkelerin özellikle konaklama fiyatını belirlerken rakip ülkelerin fiyatlarını dikkate alıyor olması etkili olabilir. Dolayısıyla bu sonucun farklı çalışmalarla ayrıca incelenmesi önerilmektedir. Sonuç olarak, bu çalışmada geleneksel yaklaşımlardan daha etkin sonuçlar veren GİR yönteminin birden çok ülkeden Türkiye'ye yönelik turizm talep tahmininde kullanılması önerilmektedir.

\section{Kaynakça}

Aksakal, M. \& Çilan, C.A. (2015). Türkiye'ye Yönelik Turizm Talebinin Görünürde İlişkisiz Regresyon Modelleri İle İncelenmesi. Uluslararasi İktisadi ve İdari İncelemeler Dergisi, 7(14), 235-256.

Baldigara, T. (2013). Forecasting Tourism Demand in Croatia: A Comparison of Different Extrapolative Methods. Journal of Business Administration Research, 2(1), 8492.

Baltagi, B., Garvin, S. \& Kerman, S. (1989). Further Monte Carlo Evidence on Seemingly Unrelated Regressions with Unequal Number of Observations. Annales D'Economie et de Statistique, 14, 103-115.

Chen, C-F. \& Soo, K. T. (2007). Cost Structure and Productivity Growth of the Taiwanese International Tourist Hotels. Tourism Management, 28, 1400-1407.

Çuhadar, M. (2013). Türkiye'ye Yönelik Dış Turizm Talebinin MLP, RBF ve TDNN Yapay Sinir Ağı Mimarileri ile Modellenmesi ve Tahmini: Karşılaştırmalı Bir Analiz. Journal of Yasar University, 8(31), 5274-5295.

Grouch, G.I, (1992). Effect of Income and Price on International Tourism to Australia. Tourism Management, June, 196-208.

Hwang, Hae-Shin (1990). Estimation of Linear SUR Model with Unequal Numbers of Observations. Review of Economics and Statistics, 72, 510-515.

Keskin, H. İ. (2018). Seçilmiş Ülkelerden Türkiye'ye Yönelik Turizm Talebinin Çok Değişkenli Çoklu Regresyon Analiziyle İncelenmesi, 3. Uluslararası Mesleki ve Teknik Bilimler Kongresi, Gaziantep, 21-21 Haziran, Türkiye.

Kmenta, Jan (1986), Elements of Econometrics. New York: Macmillan Publishing Company.

Kontoghiorghes, E. J., \& Clarke, M. R. B. (1995). An Alternative Approach for the Numerical Solution of Seemingly Unrelated Regression Equations Models. Computational Statistics \& Data Analysis, 19(4), 369-377.

Mehmetoglu, M. (2010). Factors Influencing the Willingness to Behave Environmentally Friendly At Home and Holiday Settings. Scandinavian Journal of Hospitality and Tourism, 10(4), 430-447.

O'Hagan, J. W., \& Harrison, M. J. (1984a). UK and US Visitor Expenditure in Ireland: Some Econometric Findings. Economic and Social Review, 15(3), 195-207. 
O'Hagan, J. W., \& Harrison, M. J. (1984b). Market Shares of US Tourist Expenditure in Europe: An Econometric Analysis. Applied Economics, 16(6), 919-931.

Önder, A. Ö., Candemir, A. \& Kumral, N. (2009). An Empirical Analysis of the Determinants of International Tourism Demand: The Case of Izmir. European Planning Studies, 17(10), 1525-1533.

Rufino, C. C. (2011). Forecasting International Demand for Philippine Tourism. DLSU Business \& Economics Review, (21)1, 61-76.

Salman, K. A. , Arnesson, L., Sorensson, A. \& Shukur, G.(2010). Estimating International Tourism Demand for Selected Regions in Sweden and Norway with Iterative Seemingly Unrelated Regressions (ISUR). Scandinavian Journal of Hospitality and Tourism, 10(4), 395-410.

Selim, S. \& Demir, Ç. (2009). Türkiye'ye Gelen Turist Sayısının Öngörümlenmesi: Karşılaştırmalı Bir Analiz, 10. Ekonometri ve Ístatistik Sempozyumu, Erzurum, 27-29 Mayıs, Türkiye.

Sezer, D. (2006). Görünüşte İlişkisiz Regresyon Modelleri ve Bir Uygulama (Yüksek Lisans Tezi). Selcuk University Digital Archive Systems veri tabanından erişildi.

Syriopoulos, T. C., \& Thea Sinclair, M. (1993). An Econometric Study of Tourism Demand: The AIDS Model of US and European Tourism in Mediterranean countries. Applied Economics, 25(12), 1541-1552.

Smith, M. \& Kohn, R. (2000). Nonparametric Seemingly Unrelated Regression. Journal of Econometrics, 98(2), 257-281

Song, H. \& LI, G. (2008). Tourism Demand Modelling and Forecasting - A Review of Recent Research. Tourism Management, 29(2), 203-220.

Soysal, M. \& Ömürgönülşen, M. (2010). Türk Turizm Sektöründe Talep Tahmini Üzerine Bir Uygulama, Anatolia: Turizm Araştırmaları Dergisi, 21(1), 128-136.

Srivastava, V. K. \& Dwivedi, T. D. (1979). Estimation of Seemingly Unrelated Regression Equations: A Brief Survey. Journal of Econometrics, 10, 15-32.

Şen, A. \& Şit, M. (2015). Turizm Gelirlerinin Türkiye Ekonomisindeki Rolü ve Önemi. Dicle Üniversitesi İktisadi ve İdari Bilimler Fakültesi Dergisi, 5(8), 30-45.

Vanegas Sr., M. (2009). Tourism Demand Response by Residents of Latin American Countries. International Journal Of Tourism Research, 11, 17-29.
Witt, S.F. \& Martin, C. A. (1987) Deriving a Relative Price Index for Inclusion in International Tourism Demand Estimation Models: Comment. Journal of Travel Research, 25(3), 38-40.

Zellner, A. (1962). An Efficient Method of Estimating Seemingly Unrelated Regressions and Tests for Aggregation Bias. Journal of the American Statistical Association, 57(298), 348-368.

Zellner, A. \& Huang S. (1962). Further Properties of Efficient Estimators for Seemingly Unrelated Regression Equations. International Economic Review, 3(3), 300-313.

Ziramba, E. \& Moyo, B. (2013). Aggregate Outbound Tourism Demand in South Africa: An Econometric Analysis. Journal of Economics and Behavioral Studies, 5(5), 260267.

\section{Extended abstract in English}

The impact of the tourism sector to the economy has become quite important in recent years. Especially after the 1990s, the share of tourism income in the GDP increases year by year in almost all countries. The tourism sector is a very important sector in terms of providing the foreign exchange inflows needed for the development and growth of emerging countries. Also, it is important in terms of providing significant contributions to reduce unemployment by creating employment. Therefore, modeling and estimating the demand for tourism has become essential in almost all countries.

In the studies investigating the demand for tourism, although various methods have widely been used such as classical least squared method, time series models or artificial neural networks, the seemingly unrelated regression method (SUR) stands out as an alternative technique. Seemingly unrelated regression model is a regression model that is set up by more than one dependent variable with correlation between them and more than one explanatory variable with no linear relationship between them. The benefit of this model is that the SUR estimators utilize that the relation between the equations present in the error correlation of the cross regressions, and hence it is more efficient than single equation estimation methods such as ordinary least squares (Salman et.al, 2010). This study aims to investigate the demand for tourism to Turkey from selected countries for the period 1984 - 2014 by using Seemingly Unrelated Regression (SUR) method. 
The SUR method was first developed by Zeller (1962). He found that estimating the equations together with Generalized Least Squares (GLS) method gives more effective results than estimating every equation in the regression system separately. The SUR model is a preferred method in case of demand research for commercial products, financial asset pricing models or investment models for more than one firm or sector. It is also used in tourism demand research when panel data is available. Although the SUR model is widely used in micro-economic studies, there are a limited number of studies in the tourism economics literature. Some studies using this method include: Syriopoulos and Thea (1993), O'Hagan and Harrison (1984a; 1984b), Chen and Soo (2007), Salman et.al. (2010). There is only one study that investigated tourism demand for Turkey by using SUR method, Aksakal and Çilan (2015).

In our study, the traditional demand theory has been used to research the demand for tourism of Turkey. Traditional demand theory basically focuses on four factors that explain demand: the prices of goods, the prices of substitute goods, consumer income, and consumer tastes and preferences.

The dependent variables in our model show the total number of tourists who come from selected countries to Turkey separately. Independent variables in the model are price indexes of the countries bordering the Mediterranean Sea that compete with Turkey in tour- ism, which this variable demonstrate the price of substitute goods in the model, GDP per capita of the tourist sender countries and Turkey's tourism price index.

In the study, the correlation between the error terms of the equations set up for each of the selected countries is examined by the Breusch-Pagan (1979) test. The results show that the error terms of different equations correlate with each other. So, the demand model should be estimated by using SUR models rather than OLS method for each country selected in this study separately. According the results obtained the SUR model estimation, Turkey's tourism price index doesn't seem to explain the demand significantly. Another result obtained from the study shows that an increase in rival countries' price index increases the tourism demand for Turkey. Also, an increase in the income level of the countries sending tourist seems to increase the tourism demand in general. In addition, it is seen that the price is a decisive factor for the countries with low per capita income levels when they are preferred among alternative countries for holidays. In this study, the diagnostic tests related to the predicted model are also conducted to check model assumptions. As a result of the diagnostic tests, the model does not present autocorrelation, heteroscedasticity and multicollinearity problems. As a result, it is recommended to use the SUR method in the estimation of demand for tourism from multiple countries to Turkey, which provides more efficient results than the traditional approaches. 